\section{(6) OPEN ACCESS}

\title{
Trends and social differentials in child mortality in Rwanda 1990-2010: results from three demographic and health surveys
}

\author{
Aimable Musafili, ${ }^{1,2}$ Birgitta Essén, ${ }^{2}$ Cyprien Baribwira, ${ }^{3}$ Agnes Binagwaho, ${ }^{4,5,6}$ \\ Lars-Åke Persson, ${ }^{2}$ Katarina Ekholm Selling ${ }^{2}$
}

\begin{abstract}
- Additional material is published online only. To view please visit the journal online (http://dx.doi.org/10.1136/jech2014-204657)

${ }^{1}$ Department of Paediatrics and Child Health, College of Medicine and Health Sciences, University of Rwanda, Huye, Rwanda

${ }^{2}$ Department of Women's and Children's Health, International Maternal and Child Health (IMCH), Uppsala University, Uppsala, Sweden ${ }^{3}$ Maternal and Child Health Pediatric HIV-AIDS, PMTCTRwanda Program of the Institute of Human Virology, School of Medicine, University of Maryland, Kigali, Rwanda ${ }^{4}$ Ministry of Health, Kigali, Rwanda

${ }^{5}$ Harvard Medical School, Boston, Massachusetts, USA ${ }^{6}$ Geisel School of Medicine, Dartmouth College, Hanover, New Hampshire, USA
\end{abstract}

\section{Correspondence to} Dr Aimable Musafili, Department of Women's and Children's Health, International Maternal and Child Health (IMCH), Uppsala University, Uppsala SE-751 85, Sweden; aimable.musafili@kbh.uu.se

Received 10 July 2014 Revised 17 November 2014 Accepted 6 March 2015 Published Online First 13 April 2015



CrossMark

To cite: Musafili $A$,

Essén B, Baribwira C, et al.

J Epidemiol Community

Health 2015:69:834-840.

\section{ABSTRACT}

Background Rwanda has embarked on ambitious programmes to provide equitable health services and reduce mortality in childhood. Evidence from other countries indicates that advances in child survival often have come at the expense of increasing inequity. Our aims were to analyse trends and social differentials in mortality before the age of 5 years in Rwanda from 1990 to 2010.

Methods We performed secondary analyses of data from three Demographic and Health Surveys conducted in 2000, 2005 and 2010 in Rwanda. These surveys included 34790 children born between 1990 and 2010 to women aged $15-49$ years. The main outcome measures were neonatal mortality rates (NMR) and under-5 mortality rates (U5MR) over time, and in relation to mother's educational level, urban or rural residence and household wealth. Generalised linear mixed effects models and a mixed effects Cox model (frailty model) were used, with adjustments for confounders and cluster sampling method.

Results Mortality rates in Rwanda peaked in 1994 at the time of the genocide (NMR 60/1000 live births, 95\% Cl 51 to 65 ; U5MR 238/1000 live births, $95 \% \mathrm{Cl}$ 226 to 251). The 1990s and the first half of the 2000s were characterised by a marked rural/urban divide and inequity in child survival between maternal groups with different levels of education. Towards the end of the study period (2005-2010) NMR had been reduced to $26 / 1000(95 \% \mathrm{Cl} 23$ to 29$)$ and U5MR to $65 / 1000$ (95\% Cl 61 to 70$)$, with little or no difference between urban and rural areas, and household wealth groups, while children of women with no education still had significantly higher U5MR.

Conclusions Recent reductions in child mortality in Rwanda have concurred with improved social equity in child survival. Current challenges include the prevention of newborn deaths.

\section{INTRODUCTION}

In 2012, it was estimated that 6.6 million children worldwide die each year before reaching their fifth birthday. Forty-four per cent of these deaths occur during the neonatal period, and almost all are in low-income and middle-income countries. Although a remarkable decrease in under-5 mortality (U5M) has been noted over the past two decades, the rate of decline remains inadequate, particularly in sub-Saharan Africa. ${ }^{1}$ Efforts are needed to improve child survival in these countries and prioritise neonatal mortality, which represents a considerable proportion of under-5 deaths. Improved coverage of cost-effective programmes may reduce social gaps in child survival, ${ }^{2-4}$ while targeted interventions can ensure that those most in need are reached. ${ }^{56}$

Rwanda, one of the poorest countries in the world, experienced a civil war beginning in 1990 . It was followed by the 1994 genocide, which left more than one million people dead and devastated a national economy that was already precarious. ${ }^{78}$ After this tragedy, rebuilding the country started and from 1999 onwards, comprehensive social and health reforms were scaled up, ${ }^{7} 10$ including the strengthening of all health system components. ${ }^{11} 12$ In order to reduce social inequities, the Rwandan government supports vulnerable groups, including orphans, dependent genocide survivors, disabled people, historically marginalised groups and those living in extreme poverty. ${ }^{13}$

Against this background, Rwanda provides an instructive context for the analysis of temporal equity trends in child survival. The aim of this study was to examine social differentials in mortality before the age of 5 , and to ask whether mortality reduction has concurred with improved equity in child survival.

\section{METHODS}

\section{Data}

The data were derived from three Rwandan Demographic and Health Surveys (DHS) conducted in 2000, 2005 and $2010 .{ }^{14}$ In these cross-sectional surveys, a two-stage stratified cluster sampling method was employed. From sampled households, 35413 women between the ages of 15 and 49 were successfully interviewed (figure 1). The response rate was $98 \%$ in 2000 and 2005, and $99 \%$ in 2010 . The women were interviewed about their reproductive history, the survival of their offspring, and their personal and household socioeconomic characteristics.

We restricted analyses to children born from 1 January 1990 to 31 December 2010. In order to avoid overlap between surveys, the 2000 data were limited to the preceding 10 years (1990-1999), the 2005 survey to the preceding 5 years (2000-2004) and the final 2010 survey to the preceding 6 years (2005-2010). The weighted sample size was 15198 births in 2000, 8753 in 2005 and 10848 in 2010 (figure 1).

\section{Setting}

Rwanda, with a population of approximately 10.6 million and an average of 416 people per $\mathrm{km}^{2}$, is 
ranked the most densely populated country in Africa, ${ }^{15}$ with $87 \%$ of its inhabitants living in rural areas. ${ }^{8}$ In 2010, literacy was estimated at $82 \%$ in men and $77 \%$ in women. ${ }^{15}$ The estimated gross domestic product per capita at current prices was US\$352 in 1990, US\$132 in 1994, US\$225 in 2000 and US $\$ 540$ in 2010 . $^{16}$ Rwanda is divided into 5 provinces and 30 districts that include 14980 villages, the country's smallest administrative unit. The total number of villages sampled was 445 in 2000, 462 in 2005 and 492 in 2010.

\section{Outcomes and socioeconomic characteristics}

The main outcomes are neonatal mortality (defined in the DHS as deaths 0-29 days/1000 live births) and mortality before the age of 5 years (deaths from birth up to 5 years/1000 live births). Maternal education was defined as the highest level of education attained, classified into 'no formal education', 'primary education', or 'secondary or higher level of education'. Household wealth quintiles were used as a proxy for household socioeconomic status ${ }^{14}{ }^{17}$ and were distributed into three categories by merging the two 'richest' quintiles into 'richer' and the two 'poorest' into 'poorer'. By design, this score is not comparable across the different surveys and is only used in analysis of the last survey data (2010).

\section{Analysis}

Four time periods were considered: 1990-1994 (war and genocide), 1995-1999 (post-conflict period), 2000-2004 and 20052010 (major social and health reforms). Trends in mortality were graphically represented with 3-year moving averages. Mortality rates were calculated with $95 \%$ CIs. Owing to the sampling method, weighting was applied for all descriptive statistics to correctly represent the country.

The effect of maternal educational level, residence and household wealth on neonatal mortality was analysed using generalised linear mixed effects models (GLMM), R package 'Ime4'. ${ }^{18}$ The association between determinants and U5M was retrieved by using a mixed-effect Cox model (frailty model), R package 'coxme'. ${ }^{19}$ In the crude models, each main determinant was included as a fixed factor nested within the random factor primary sample unit (PSU). In the adjusted models, all main predictors were simultaneously entered into the model, together with maternal age in years $(<20,20-34$, or $>34)$, birth order (1st birth, 2nd to 6th birth, or $>6$ th birth) and sex of child (male or female); all were treated as fixed factors nested within PSU. The GLMM and frailty models were used for the period 2005-2010, almost six years after initiating major social and health reforms, to analyse equity in child survival as compared

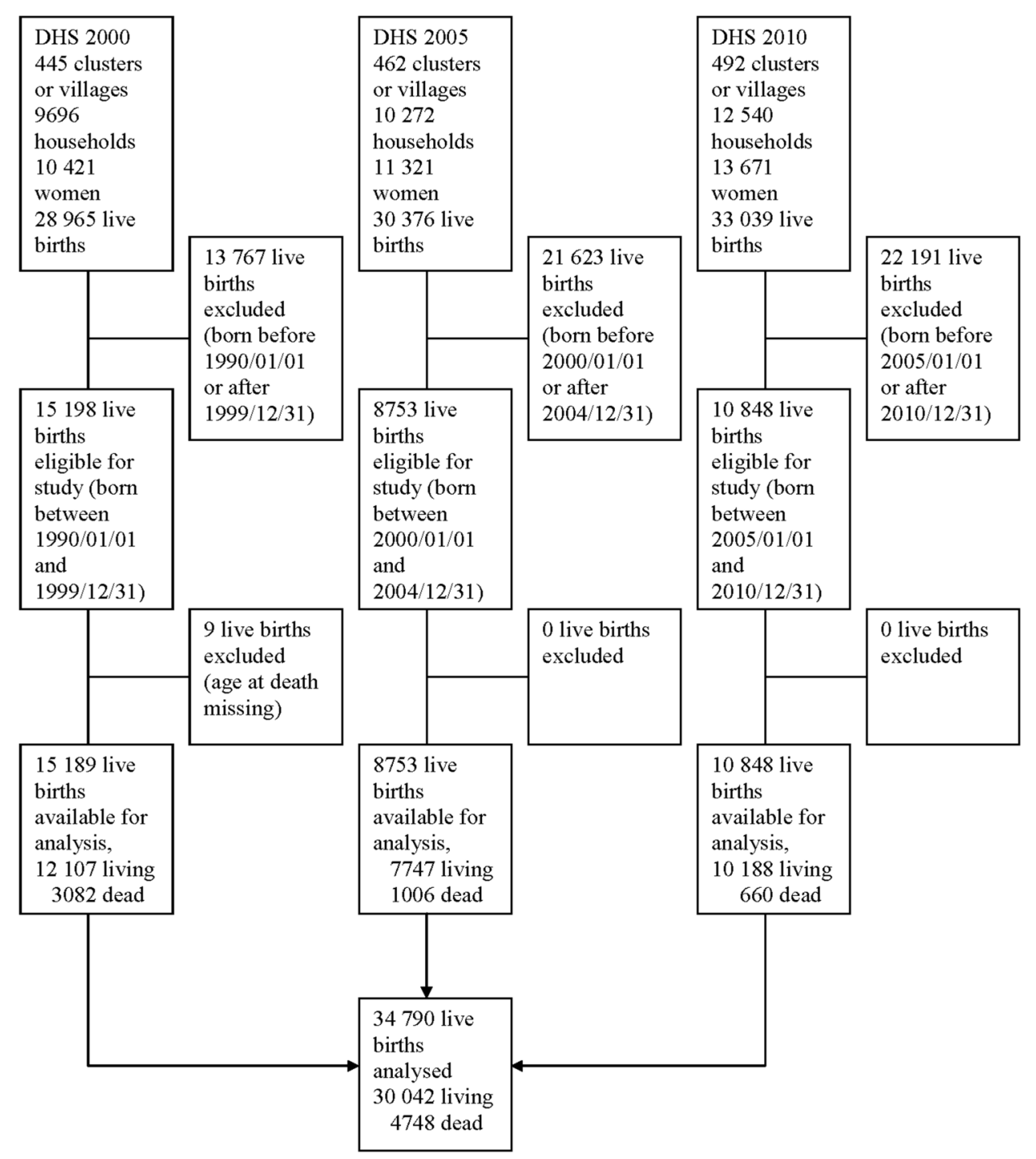

Figure 1 Flow chart of study population (DHS, Demographic and Health Survey). 
Table 1 Number of live births and under-5 deaths (0-59 months)

\begin{tabular}{|c|c|c|c|c|}
\hline Source of data & DHS 2000 & DHS 2000 & DHS 2005 & DHS 2010 \\
\hline Follow-up period & 1990-1994 & 1995-1999 & $2000-2004$ & $2005-2010$ \\
\hline Live births & 7356 & 7833 & 8753 & 10848 \\
\hline \multicolumn{5}{|l|}{ Deaths } \\
\hline Neonatal (<1 month) & 416 & 351 & 317 & 278 \\
\hline Postneonatal (1-11 months) & 456 & 503 & 419 & 263 \\
\hline Child (12-59 months) & 412 & 664 & 302 & 165 \\
\hline Neonatal deaths per 1000 live births $(95 \% \mathrm{CI})$ & 57 (51 to 62) & 45 (41 to 50$)$ & 36 (33 to 40$)$ & $26(23$ to 29$)$ \\
\hline Under-5 deaths per 1000 live births $(95 \% \mathrm{CI})$ & 175 (166 to 183$)$ & 194 (185 to 203$)$ & 119 (112 to 126$)$ & 65 (61 to 70$)$ \\
\hline
\end{tabular}

with the previous period. The analyses were limited to records having complete data.

\section{Ethical approval}

New ethical approval was not necessary since the study was a secondary analysis of demographic and health survey data.

\section{RESULTS}

From 1990 to 2010, 34799 children were born to the women surveyed. Nine children were excluded from the analyses because their age at death was unknown (figure 1). Of the 34790 live births (17 579 boys, 17211 girls) available for analysis, 1362 (781 boys, 581 girls) died during the neonatal period (39/1000 live births; 95\% CI 37 to 41/1000 live births) and 4546 (2373 boys, 2173 girls) died before reaching their fifth birthday (131/1000 live births; 95\% CI 127 to $134 / 1000$ live births). The highest death rates in newborns (57/1000 live births; 95\% CI 51 to 62), and in children younger than 5 years (194/1000 live births; 95\% CI 185 to 203) occurred during the periods 1990-1994 and 1995-1999, respectively (table 1 and figure 2).

A second peak in mortality in 1997 followed a peak at the time of the genocide (figure 2). In the latest period covered by DHS 2010 (2005-2010), the neonatal mortality rate had been reduced to $26 / 1000$ live births (95\% CI 23 to 29), and mortality before the age of 5 years was $65 / 1000$ live births (95\% CI 61 to 70) (table 1 and figure 2).
The level of maternal education increased over time. Most children were born to mothers whose education was limited to primary school and who lived in rural areas (see online supplementary table S1).

The highest U5M rates were observed among children born to women with no formal education (table 2 and online supplementary figure S1). Child mortality decreased as maternal education increased during the last 6 years studied.

There was an urban/rural divide in mortality that also decreased over time (table 2 and online supplementary figure S2). In the last period (2005-2010), there were also relatively small differences in U5M between household wealth strata (table 2).

No statistically significant association was found between socioeconomic determinants (maternal education level, household residence and household wealth) and neonatal mortality from 2005 to 2010 (table 3).

Boys had higher neonatal mortality than girls. Maternal education level continued to be associated with U5M during the period cited, even after adjustment for potential confounders and other factors (table 4). Neither rural residency nor household wealth were associated with U5M in either crude or adjusted analyses.

\section{DISCUSSION}

Political developments in Rwanda from 1990 to 2010 are reflected in temporal trends in neonatal and U5M. The peak in
Figure 2 Neonatal, infant and under-5 mortality rates in Rwanda (3-year moving averages), 1990-2010. Analysis of Demographic and Health Surveys data.

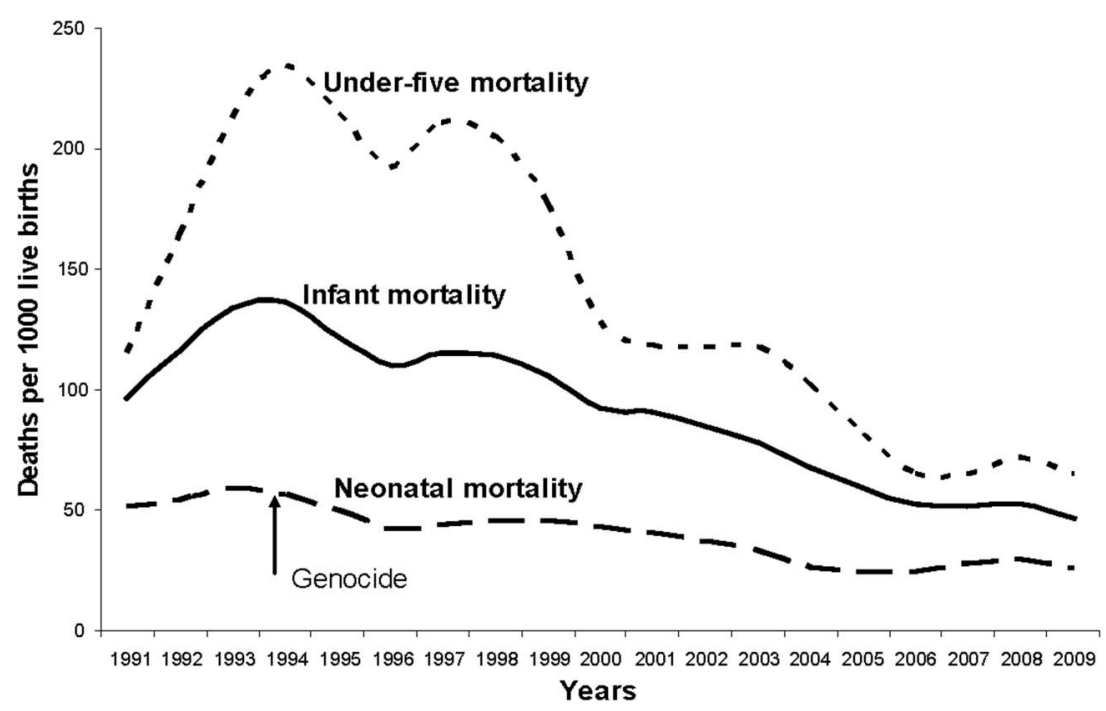


Table 2 Mortality rates before the age of 5 years, 1990-2004 and 2005-2010, and in different strata (maternal educational levels, urban or rural residence and household wealth levels)

\begin{tabular}{|c|c|c|c|c|c|c|}
\hline \multirow[b]{2}{*}{ Characteristic } & \multicolumn{3}{|l|}{ 1990-2004 } & \multicolumn{3}{|l|}{ 2005-2010 } \\
\hline & Live births & Deaths & Rate per 1000 live births $(95 \% \mathrm{Cl})$ & Live births & Deaths & Rate per 1000 live births $(95 \% \mathrm{Cl})$ \\
\hline All & 23942 & 3840 & $160(156$ to 165$)$ & 10848 & 706 & 65 (61 to 70$)$ \\
\hline \multicolumn{7}{|l|}{ Maternal education } \\
\hline Secondary or higher & 2032 & 185 & $91.0(79.3$ to 104$)$ & 954 & 49 & 51 (39 to 67$)$ \\
\hline Primary & 13269 & 2012 & 152 (146 to 158$)$ & 7752 & 484 & 62 (57 to 68$)$ \\
\hline No formal education & 8641 & 1643 & 190 (182 to 199$)$ & 2142 & 173 & 81 (70 to 93$)$ \\
\hline \multicolumn{7}{|l|}{ Maternal residence } \\
\hline Urban & 3249 & 355 & 109 (99.0 to 120$)$ & 1292 & 75 & 58 (47 to 72$)$ \\
\hline Rural & 20693 & 3485 & 168 (163 to 174$)$ & 9556 & 631 & 66 (61 to 71$)$ \\
\hline \multicolumn{7}{|l|}{ Household wealth* } \\
\hline Richer & & & & 3854 & 226 & 59 (58 to 67$)$ \\
\hline Middle & & & & 2156 & 147 & 68 (58 to 80$)$ \\
\hline Poorer & & & & 4838 & 333 & 69 (62 to 76$)$ \\
\hline
\end{tabular}

Data weighted using sample weight factor from the Demographic and Health Surveys to obtain representative nationwide estimates. Household wealth strata only shown for most recent time period, since relative household asset scores not comparable across different Demographic and Health Surveys.

*Two richest and two poorest quintiles were dichotomised as 'richer' and 'poorer' quintiles.

death rates during the genocide period and the subsequent work to rebuild society were followed by the political successes of the 2000 s that reshaped mortality curves. Neonatal mortality reduction, however, has been smaller and calls for greater action. Reduced mortality has been accompanied with increasing social equity in child survival, especially regarding urban/rural differentials. The social divide in mortality levels was also narrow among household wealth groups. Children of mothers with little or no education still show excess mortality.

\section{Strengths and limitations}

We reduced potential recall bias by restricting our analysis to children born within 10 years prior to the DHS 2000, 5 years before the DHS 2005 and 6 years preceding the DHS 2010, as described earlier. The quality of mortality data is judged to be less affected by recall errors when the events take place not more than 10 years before the survey. ${ }^{20}$ Social characteristics, such as a mother's education, residence and household wealth reflect the situation at the time of the survey. ${ }^{80}$ A woman's educational level generally does not change after the birth of her first child, although urban or rural residency and household wealth may vary over time. Again, reducing the recall period to 5 or 6 years, as was the case in the second half of the study period, would reduce this misclassification risk. The cluster sampling method was adjusted for in the analyses.

The calculation and graphical representation of mortality rates were based on a 3-year moving average. Thus, the levels of mortality reported in this study should not necessarily be comparable to those published in the Rwandan DHS reports that covered 5 years preceding each survey.

\section{Temporal trends in mortality}

In the early 1990s, mortality peaked at the time of the 1994 genocide, which also devastated human resources in the health sector and destroyed health infrastructure. ${ }^{8}$ The postgenocidal period coincided with a rapid reduction in infant and U5M, as security improved and the country benefited from strong assistance from the international community. This international support later decreased, which is perhaps responsible for the second mortality peak in the 1990s. Provision of free healthcare, which was suspended from 1994 to 1996, was thereafter reintroduced. ${ }^{21}$ The abolition of health service user fees has been shown to prevent under-5 deaths in African countries and could partly explain the reduction of deaths immediately after

Table 3 Crude and adjusted ORs from generalised linear mixed effects model of neonatal mortality risks in relation to social characteristics of mothers and households, Rwanda, 2005-2010

\begin{tabular}{|c|c|c|c|c|}
\hline \multirow[b]{2}{*}{ Characteristic } & \multicolumn{2}{|c|}{ Crude analyses* } & \multicolumn{2}{|c|}{ Adjusted analyses $t$} \\
\hline & OR & $95 \% \mathrm{Cl}$ & OR & $95 \% \mathrm{Cl}$ \\
\hline \multicolumn{5}{|l|}{ Maternal education } \\
\hline Secondary or higher & Reference & & Reference & \\
\hline Primary & 1.29 & 0.74 to 2.27 & 1.19 & 0.62 to 2.26 \\
\hline No formal education & 1.50 & 0.81 to 2.78 & 1.29 & 0.63 to 2.65 \\
\hline \multicolumn{5}{|l|}{ Household residence } \\
\hline Urban & Reference & & Reference & \\
\hline Rural & 1.35 & 0.86 to 2.12 & 1.28 & 0.67 to 2.45 \\
\hline \multicolumn{5}{|l|}{ Household wealth $\ddagger$} \\
\hline Richer & Reference & & Reference & \\
\hline Middle & 0.95 & 0.60 to 1.52 & 0.86 & 0.51 to 1.45 \\
\hline Poorer & 1.30 & 0.90 to 1.86 & 1.15 & 0.76 to 1.76 \\
\hline \multicolumn{5}{|l|}{ Maternal age (years) } \\
\hline$<20$ & & & 1.36 & 0.72 to 2.58 \\
\hline $20-34$ & & & Reference & \\
\hline$>34$ & & & 1.52 & 0.94 to 2.44 \\
\hline \multicolumn{5}{|l|}{ Birth order } \\
\hline 1st birth & & & 1.22 & 0.79 to 1.87 \\
\hline 2nd to 6th birth & & & Reference & \\
\hline$>6$ th birth & & & 0.97 & 0.54 to 1.74 \\
\hline \multicolumn{5}{|l|}{ Sex of child } \\
\hline Male & & & Reference & \\
\hline Female & & & 0.71 & 0.53 to 0.97 \\
\hline
\end{tabular}


Table 4 Crude and adjusted HRs from mixed effect Cox model (frailty model) of under-5 mortality risks by social characteristics of mothers and households, Rwanda, 2005-2010

\begin{tabular}{|c|c|c|c|c|}
\hline \multirow[b]{2}{*}{ Characteristic } & \multicolumn{2}{|c|}{ Crude analyses* } & \multicolumn{2}{|c|}{ Adjusted analysest } \\
\hline & HR & $95 \% \mathrm{Cl}$ & HR & $95 \% \mathrm{Cl}$ \\
\hline \multicolumn{5}{|l|}{ Maternal education } \\
\hline Secondary or higher & Reference & & Reference & \\
\hline Primary & 1.14 & 0.84 to 1.53 & 1.10 & 0.81 to 1.51 \\
\hline No formal education & 1.50 & 1.09 to 2.07 & 1.42 & 1.00 to 2.01 \\
\hline \multicolumn{5}{|l|}{ Household residence } \\
\hline Urban & Reference & & Reference & \\
\hline Rural & 1.14 & 0.89 to 1.48 & 1.06 & 0.80 to 1.40 \\
\hline \multicolumn{5}{|l|}{ Household wealth $\ddagger$} \\
\hline Richer & Reference & & Reference & \\
\hline Middle & 1.09 & 0.87 to 1.37 & 1.04 & 0.82 to 1.31 \\
\hline Poorer & 1.13 & 0.94 to 1.36 & 1.06 & 0.87 to 1.29 \\
\hline \multicolumn{5}{|l|}{ Maternal age (years) } \\
\hline$<20$ & & & 1.27 & 0.92 to 1.75 \\
\hline $20-34$ & & & Reference & \\
\hline$>34$ & & & 1.07 & 0.84 to 1.37 \\
\hline \multicolumn{5}{|l|}{ Birth order } \\
\hline 1st birth & & & 1.10 & 0.90 to 1.35 \\
\hline 2nd to 6 th birth & & & Reference & \\
\hline$>6$ th birth & & & 1.19 & 0.90 to 1.57 \\
\hline \multicolumn{5}{|l|}{ Sex of child } \\
\hline Male & & & Reference & \\
\hline Female & & & 0.87 & 0.74 to 1.02 \\
\hline \multicolumn{5}{|c|}{$\begin{array}{l}{ }^{*} \text { Crude analyses of under- } 5 \text { mortality performed by mixed effect Cox model (frailty } \\
\text { model). Fixed factors (maternal education, residence, household wealth) included } \\
\text { separately in models, nested within random factor cluster. } \\
\text { †Adjusted analyses of under-5 mortality performed by means of mixed effect Cox } \\
\text { model. Fixed factors (maternal education, residence, household wealth, maternal age, } \\
\text { birth order and sex of child) included simultaneously in model, nested within random } \\
\text { factor cluster. } \\
\text { †Two richest and two poorest quintiles dichotomised as 'richer' and 'poorer' quintiles. }\end{array}$} \\
\hline
\end{tabular}

the genocide. ${ }^{22}$ From the end of the 1990s scale-up of comprehensive social and health reforms, a remarkable decrease in mortality occurred. In 2010 Rwanda had a lower U5M rate than all its bordering countries. ${ }^{1}$ Nevertheless, the rate of child mortality reduction in Rwanda turns out to be insufficient to reach the Millennium Development Goal 4 by 2015. The relatively small reduction in neonatal mortality may reflect too little attention being given to the mother-and-newborn dyad and the need for neonatal survival strategies, as confirmed by reports from other low-income countries. ${ }^{23}$

\section{Key drivers of mortality reduction}

After the 1994 genocide, the Rwandan government concentrated its attention on political stability, trying to reinvigorate its national economy while receiving humanitarian assistance. In the early 2000s, the country embarked on a flagship programme known as Rwanda Vision 2020, a long-term strategy to lift Rwanda from low-income to middle-income status by the year $2020 .^{24}$ The 'One Cow per Poor Family Program', or Girinka, is one of the pro-poor efforts aimed at increasing the availability of milk and improving family incomes. ${ }^{25}$ Extreme poverty has decreased from $45 \%$ in 2000 to $24 \%$ in $2010 .^{26}$

\section{Health system strengthening}

The Rwandan government has initiated several reforms in the health sector during the last decade. These reforms relate to the six building blocks of the health system, which are interrelated and dependent on each other, as expressed by WHO. ${ }^{11}$

\section{Health services delivery}

After 2005, geographical accessibility to health services was improved by construction of five new district hospitals and 49 health centres, while 98 dispensaries and health posts were made available throughout the country. ${ }^{27}$ An emergency transportation service with 168 ambulances was also launched. ${ }^{28}$ A Maternal and Child Health Unit was formed at the Ministry of Health. Emergency Obstetric and Newborn care packages were implemented, and strategies to provide basic and intensive care in neonates were reinforced. A large number of programmes and initiatives were begun along the continuum of care for maternal, newborn and child health. Maternal mortality audits and later neonatal mortality audits were scaled up in all hospitals. The Integrated Management of Childhood Illnesses (IMCI) strategy became operational. In 2002, the Prevention of Mother to Child Transmission of HIV (PMTCT) programme was initiated and the number of health facilities offering PMTCT services increased to 382 in 2010. The immunisation schedule was expanded by the inclusion of new vaccines and vitamin A supplementation. ${ }^{29}$ The Ministry of Health also adopted a strategic plan to fight malnutrition.

\section{Human resources for health}

Formerly, health staff was unevenly distributed between rural and urban areas. The government acted to increase the quantity and quality of human resources for health. Educational institutions for health professionals were strengthened, followed by polices for the rational use of human resources, accreditation, professional training and supervision, and performance-based financing (PBF), to improve the quality of care and the retention of the health workforce. ${ }^{30}$ By 2012, the number of medical doctors had increased from 148 in 1999 to 641, and nurses and midwives from 1143 in 1999 to 8591 . Community health workers were also involved in healthcare delivery under the close supervision of health centres and district hospitals, and their numbers reached 45000 in $2010 .^{30}$

\section{Health information system}

The Rwandan Health Management Information System incorporated more modern information technologies from the late 1990s onward. The Rapid Short Message Service (RapidSMS) system was an m-Health approach to preventing maternal and infant mortality; pregnant women and infants were monitored by community health workers who notified those who required follow-up by SMS. Community health workers reported management of childhood illnesses, child nutritional status and vaccinations, and maternal health and deaths through another m-Health system called mUbuzima. ${ }^{31}$

\section{Medicines, vaccines and technologies}

The availability and quality of medicines, vaccines, consumables and medical equipment were given priority by the government. A Center for Purchasing of Essential Medicines (CAMERWA) was created at an early stage and pharmaceuticals were centrally procured for government-assisted health facilities. Private wholesale and retail pharmacies also increased the availability of medical products and consumables. ${ }^{7}$

\section{Health financing}

In 1999, a community health insurance scheme, known as Mutuelle de Santé, was established and covered 91\% of the 
population by $2010 . .^{32}$ Beginning in 2002, the PBF strategy was gradually scaled up throughout the country. ${ }^{33}$ The government budget allocated to health increased from $8.6 \%$ in 2002 to $11.5 \%$ in fiscal year $2010 .{ }^{30}$

\section{Leadership and governance}

In 1996, the government adopted the Lusaka Declaration that stresses gender equity, decentralisation of healthcare by the development of a primary healthcare system and strengthening of community participation. ${ }^{8}$ A decentralisation process of health and administrative sectors became a reality in $2006 .{ }^{34}$ Particular attention was given to supervision, evaluation, monitoring and coordination of services at all levels. Zero tolerance for corruption was emphasised, resulting in Rwanda receiving a high ranking among the least corrupt countries in the world in 2012. ${ }^{35}$ Good governance and leadership have been credited as the main contributing factors to the improved coverage of maternal health services in Rwanda. ${ }^{9}$

\section{Social differentials in mortality}

Mortality rates of children under 5 years of age are usually higher if their mothers have not attended school. ${ }^{36-38}$ This was the case in the analysis of the Rwandan data, even in the most recent survey (2005-2010), although the gap had been reduced. The education of girls may provide future mothers with more insight into potential health risks, give them improved selfconfidence, and positively influence their position in the family and society. ${ }^{39}$ The Rwandan government has recently upgraded basic education to 12 years, which may further influence child survival in a favourable direction. ${ }^{40} \mathrm{~A}$ large number of studies have demonstrated the role of poverty as a key determinant in infant and child mortality. ${ }^{36}{ }^{41}$ It should be noted that U5M did not significantly differ between richer and poorer households in 2005-2010. This may reflect a pro-poor focus in Rwandan policies that has reduced gaps in child survival. A recent analysis of DHS data on neonatal mortality from 24 low-income and middle-income countries, including Rwanda, indicated heterogeneity in results but, for most countries, a decrease in socioeconomic inequality in neonatal mortality. ${ }^{42} \mathrm{~A}$ decrease in socioeconomic inequality in mortality was also reported from a population-based study of infant mortality in Vietnam, a country where efforts have also been made to combine universal health coverage with targeted efforts for disadvantaged groups. ${ }^{37}$ The government has also initiated programmes to reduce poverty and develop the economy, especially over the last decade, with particular attention to social inequalities. ${ }^{43} \mathrm{An}$ urban/rural divide in child survival has frequently been reported..$^{39}$ In Rwanda, this gap was substantially reduced in the 2005-2010 period, and no statistical difference was thereafter noted between rural and urban areas, perhaps reflecting that the previous low coverage of opportunities and programmes in rural areas has changed. Countrywide strategies may have contributed to such improvements as the participation of community health workers in health services delivery and the traditional approach called Ubudehe, which involves the active participation of a community in addressing its own problems. ${ }^{43}$

\section{CONCLUSIONS}

Rwanda has made successful efforts during the 2000s, which have resulted in gradual decrease in child mortality and reduced social differentials in survival, but neonatal mortality rate constitutes a continuing challenge. The combination of efforts to reach universal coverage of key maternal and child interventions, combined with targeted programmes for vulnerable groups, reinforced by pro-equity efforts in other sectors of society, may further reduce the absolute levels of mortality in children and social differentials in survival.

\section{What is already known on this subject}

Rwanda has embarked on ambitious programmes to provide equitable health services and reduce mortality in childhood. Evidence from other countries indicates that advances in child survival have often come at the expense of increasing inequity.

\section{What this study adds}

An impressive reduction in mortality before the age of 5 years has taken place in Rwanda between the years 1990 and 2010, and has concurred with increased social equity in child survival (rural/ urban and wealth disparity), while children born to mothers with little education still have higher mortality.

Acknowledgements The authors would like to thank the Swedish International Development Cooperation Agency (Sida) for the opportunity provided to AM for the PhD fellowship awarded to him.

Contributors L-ÅP planned the study with contributions from $A M, B E, C B$ and KES. AM abstracted data and prepared files for analysis. AM, KES and L-ÅP performed data analysis and interpreted results with substantial contributions from the other co-authors. AM drafted the manuscript, which was critically revised by all co-authors. All authors have read and approved the final version of this manuscript for submission.

Competing interests $A B$ is Minister of Health, Rwanda.

Provenance and peer review Not commissioned; externally peer reviewed.

Open Access This is an Open Access article distributed in accordance with the Creative Commons Attribution Non Commercial (CC BY-NC 4.0) license, which permits others to distribute, remix, adapt, build upon this work non-commercially, and license their derivative works on different terms, provided the original work is properly cited and the use is non-commercial. See: http://creativecommons.org/ licenses/by-nc/4.0/

\section{REFERENCES}

1 UN Inter-agency Group for Child Mortality Estimation. Level \& trends in child mortality: report 2013. New York: United Nations Children's Fund, 2013 (cited 1 Jan 2014). http://www.who.int/maternal_child_adolescent/documents/levels_trends_ child_mortality_2013.pdf?ua=1

2 Victora CG, Fenn B, Bryce J, et al. Co-coverage of preventive interventions and implications for child-survival strategies: evidence from national surveys. Lancet 2005;366:1460-6.

3 Victora CG, Barros AJ, Axelson $\mathrm{H}$, et al. How changes in coverage affect equity in maternal and child health interventions in 35 Countdown to 2015 countries: an analysis of national surveys. Lancet 2012;380:1149-56.

4 Chopra M, Sharkey A, Dalmiya N, et al. Strategies to improve health coverage and narrow the equity gap in child survival, health, and nutrition. Lancet 2012;380:1331-40.

5 Bhutta ZA, Chopra M, Axelson H, et al. Countdown to 2015 decade report (2000-10): taking stock of maternal, newborn, and child survival. Lancet 2010;375:2032-44.

6 Victora CG, Wagstaff A, Schellenberg JA, et al. Applying an equity lens to child health and mortality: more of the same is not enough. Lancet 2003;362:233-41.

7 National Institute of Statistics of Rwanda. Service provision assessment survey 2007. Kigali, Rwanda, 2008 (cited 3 Feb 2014). http://www.populationmedia.org/ wp-content/uploads/2009/03/rwanda-hiv-mch-spa-2007.pdf

8 National Institute of Statistics of Rwanda, Ministry of Health, ICF International. Rwanda demographic and health survey 2010. Calverton, MD, 2012 (cited 1 Feb 2014). http://statistics.gov.rw/publications/demographic-and-health-survey-2010final-report

9 Bucagu M, Kagubare JM, Basinga $\mathrm{P}$, et al. Impact of health systems strengthening on coverage of maternal health services in Rwanda, 2000-2010: a systematic review. Reprod Health Matters 2012;20:50-61. 
10 Farmer $\mathrm{PE}$, Nutt $\mathrm{CT}$, Wagner $\mathrm{CM}$, et al. Reduced premature mortality in Rwanda: lessons from success. BMJ 2013;346:f65.

11 World Health Organization. Everybody's business: strengthening health systems to improve health outcomes: Geneva: WHO's framework for action, 2007 (cited 25 Jan 2014). http://www.who.int/healthsystems/strategy/everybodys_business.pdf

12 Republic of Rwanda Ministry of Health. Health sector strategic plan: July 2009-June 2012. Kigali, Rwanda, 2009 (cited 5 Feb 2014). https://www.google.rw/url? sa $=t \& r c t=i \& q=\& e s r c=s \&$ source $=$ web\& $\& d=4 \&$ ved $=0$ CDkQFjAD\&url $=h t t p \% 3 A \%$ 2F\%2Fwww.ipar-rwanda.org\%2Findex.php\%3Foption\%3Dcom_docman\% 26task\%3Ddoc_download\%26gid\%3D91\%26ltemid\%3D151\&ei= eCnxUs2uBoeBywODqoDQAw\&usg=AFQjCNGwEGj0830XwYD22k9wyaPwPg90cg

13 Minister of Local Government, Rwanda. National social protection strategy, Rwanda. Kigali, Rwanda, 2011 (cited 3 Feb 2014). http://www.ilo.org/gimi/gess/ ShowRessource. action? ressource. .ressourceld $=23208$

14 ICF Macro. Demographic and health surveys. Calverton, MD, 2013 (cited 13 Aug 2013). http://www.measuredhs. com/What-We-Do/survey-search.cfm? pgtype $=$ main\&SryyTp=country. $\% 20$ Accessed $\% 202013-20-09$

15 National Institute of Statistics of Rwanda. 2012 Population and housing census (provisional results). Kigali, Rwanda, 2012 (cited 14 Dec 2013). http://www. statistics.gov.rw/publications/2012-population-and-housing-census-provisional-results

16 National Institute of Statistics of Rwanda. 2012 GDP annual estimates. Kigali, Rwanda, 2013 (cited 2 Feb 2014). http://www.statistics.gov.rw/publications/gdpnational-accounts-2012

17 Gwatkin DR, Rustein $\mathrm{S}$, Johnson $\mathrm{K}$, et al. Socio-economic differences in health nutrition, and population in Bangladesh. Washington, DC: World Bank, 2000 (cited 25 Feb 2014). http://siteresources.worldbank.org/INTPAH/Resources/Publications/ Country-Reports/bangladesh.pdf

18 Bates D, Maechler M, Bolker B, et al. Ime4: Linear mixed-effects models using Eigen and S4. R package version 0.999999-0. 2012 (cited 4 Jun 2013). http:// CRAN.R-project.org/package $=$ Ime 4

19 Therneau T. Coxme: Mixed effects Cox models. R package version 2.2-3. 2012 (cited 15 Jun 2013). http://CRAN.R-project.org/package=coxme

20 Curtis SL. Assessment of the quality of data used for direct estimation of infant and child mortality in DHS-II surveys. Occasional papers No. 3. Calverton, MD: Macro International Inc., 1995 (cited 2 Feb 2014). http://www.measuredhs.com/pubs/pdf/ OP3/OP3.pdf

21 Pose Rodriguez R, Samuels F. Rwanda's progress in health: leadership, performance, and insurance. London: Overseas Development Institute, 2011 (cited 3 Feb 2014]. http://www.developmentprogress.org/sites/developmentprogress.org/files/ rwanda_report_-_master_0.pdf

22 James $C$, Morris $S S$, Keith $R$, et al. Impact on child mortality of removing user fees: simulation model. BMJ 2005:331:747-9.

23 Lawn JE, Kinney MV, Black RE, et al. Newborn survival: a multi-country analysis of a decade of change. Health Policy Plan 2012;27(Suppl 3):iii6-28.

24 Republic of Rwanda. Rwanda vision 2020. 2000 (cited 27 Dec 2013). http://www. minecofin.gov.rw/fileadmin/General/Vision_2020/Vision-2020.pdf

25 Republic of Rwanda Ministry of Agriculture and Animal Resources. One cow per poor family program "GIRINKA". Kigali, Rwanda, 2013 (cited 15 Jun 2013). http:// www.minagri.gov.rw/index.php?id $=28 \& L=0$

26 National Institute of Statistics of Rwanda. Statistical yearbook 2012. Kigali, Rwanda, 2012 (cited 3 Feb 2014). http://www.statistics.gov.rw/publications/ statistical-yearbook-2012
27 Republic of Rwanda Ministry of Health. Rwanda health statistics booklet 2011. Kigali, Rwanda, 2012 (cited 2 Feb 2014). http://www.moh.gov.rw/fileadmin/ templates/HMIS_Docs/MOH_Annual_booklet-2011.pdf

28 Republic of Rwanda Ministry of Health. Annual report, 2008. Kigali, Rwanda, 2009 (cited 24 Jan 2014). http://www.moh.gov.rw/fileadmin/templates/MOH-Reports/ Final-MoH-annual-report-2008.pdf

29 Republic of Rwanda Ministry of Health. Comprehensive multi-year plan, 20132017. Kigali, Rwanda: Rwanda Biomedical Center, Institute of HIV/AIDS Disease Prevention \& Control, Vaccine Preventable Diseases Division, 2012 (cited 2 Feb 2014). ftp://iff-immunisation.org/MannionDaniels/HSFP\%20review\%20May\% 202012/Rwanda_Resubmission/Attachment\%201/Annex\%201c\%20Rwanda\% 20Vaccine\%20Preventable\%20Disease\%20Strategic\%20plan\%20(cMYP).doc

30 Republic of Rwanda Ministry of Health. Annual report, 2011-2012. Kigali, Rwanda, 2012 (cited 1 Feb 2014). http://www.moh.gov.rw/fileadmin/templates/MOH-Reports/ MoH-Annual-Report-July-2011-June-2012.pdf

31 World Health Organization. Assisting community health workers in Rwanda: MOH's RapidSMS and mUbuzima, 2013 (cited 27 Dec 2013). http://apps.who.int/iris/ bitstream/10665/92814/1/WHO_RHR_13.15_eng.pdf

32 Republic of Rwanda Ministry of Health. Key indicators. Kigali, Rwanda, 2012 (cited 27 Dec 2013). http://www.moh.gov.rw/index.php?id=3

33 Rusa L, Ngirabega Jde D, Janssen W, et al. Performance-based financing for better quality of services in Rwandan health centres: 3-year experience. Trop Med Int Health 2009;14:830-7.

34 World Health Organization. WHO country cooperation strategy 2009-2013: Rwanda. Brazzaville, Republic of Congo: WHO Regional Office for Africa, 2009 (cited 24 Dec 2013) http://www.who.int/countryfocus/cooperation_strategy/ccs_rwa_en.pdf

35 Transperancy International. Corruption perceptions index 2012. Berlin, 2013 (cited 27 Dec 2013). http://www.transparency.org/cpi2012/results

36 Peña R, Wall S, Persson LA. The effect of poverty, social inequity, and maternal education on infant mortality in Nicaragua, 1988-1993. Am J Public Health 2000:90:64-9

37 Hoa DP, Nga NT, Målqvist M, et al. Persistent neonatal mortality despite improved under-five survival: a retrospective cohort study in northern Vietnam. Acta Paediatr 2008;97:166-70

38 Pérez W, Peña R, Persson $L \AA$, et al. Tracking progress towards equitable child survival in a Nicaraguan community: neonatal mortality challenges to meet the MDG 4. BMC Public Health 2011:11:455.

39 Macassa G, Hallqvist J, Lynch JW. Inequalities in child mortality in sub-Saharan Africa: a social epidemiologic framework. Afr J Health Sci 2011;18:14-26.

40 Republic of Rwanda Ministry of Education. Forward-looking joint review of the education sector: summary report. Kigali, Rwanda, 2012 (cited 18 Jan 2014). http:/ www.mineduc.gov.rw/IMG/pdf/Foward_looking_report_EDPRS1.pdf

41 Houweling TA, Kunst AE. Socio-economic inequalities in childhood mortality in lowand middle-income countries: a review of the international evidence. Br Med Bull 2010;93:7-26.

42 McKinnon B, Harper S, Kaufman SJ, et al. Socioeconomic inequality in neonatal mortality in countries of low and middle income: a multicountry analysis. Lancet 2014;2:165-73.

43 Republic of Rwanda Ministry of Finance and Economic Planning. Economic development and poverty reduction strategy 2008-2012. Kigali, Rwanda, 2007 (cited 30 Jan 2014). http://www.statistics.gov.rw/publications/economicdevelopment-poverty-reduction-strategy-2008-2012 